\title{
CREEP CRACK INITIATION AND GROWTH IN THICK SECTION STEEL PIPES UNDER INTERNAL PRESSURE
}

\author{
K. Wasmer, K. M. Nikbin* and G. A. Webster
}

Dept. of Mechanical Engineering

Imperial College

London, SW7 2BX

\begin{abstract}
In this study, creep crack growth in pre-cracked straight and bent pipes of a 9\% Cr-steel, containing multiple cracks and tested at $625^{\circ} \mathrm{C}$ under static and slow cyclic pressure loading, is investigated. The results have been interpreted in terms of the creep fracture mechanics parameter $C^{*}$ and compared with data obtained on standard compact tension (CT) specimens of the same material and batch. In making the assessments, reference stress methods have been used to determine $C^{*}$ for the pipes. Several formulae can be employed for calculating reference stress depending on whether it is based on a 'global' or a 'local' collapse mechanism. When using this approach, it is shown that the values obtained for $C^{*}$ are sensitive to the material properties, geometric dimensions and crack lengths chosen in the analysis. However, it has been found that, the most satisfactory comparison of crack growth rates with standard CT specimen data is obtained when the 'global' reference stress solution is used in conjunction with the nominal thickness of a pipe and the mean parent uniaxial creep properties. Also, no difference has been observed between the crack growth rates measured in the straight and bent pipes. The main effect of the slow pressure cycling was to cause an acceleration in the early stages of cracking.
\end{abstract}

KEY words: Defects, fracture mechanics, creep crack growth, pipe components.

Corresponding author ${ }^{*}$ K. M. Nikbin, Mechanical Engineering, Imperial College, London, SW7 2AZ, fax: 0207-5947107, e-mailk.nikbin@imperial.co.uk 
NOMENCLATURE

\begin{tabular}{|c|c|}
\hline$A$ & Norton power law creep constant in Eq. (3) \\
\hline$C^{*}$ & steady state creep fracture mechanics parameter \\
\hline$C_{r e f}^{*}$ & value of $C^{*}$ determined from reference stress methods \\
\hline$D$ & constant in Eq. (1) \\
\hline$\overline{D_{i}}$ & constant in Eq. (5) \\
\hline$J$ & elastic-plastic fracture mechanics parameter \\
\hline$K$ & stress intensity factor \\
\hline$R_{i}, R_{e}$ & internal and external radii of cylinder \\
\hline$W$ & cylinder wall thickness \\
\hline$a, a_{i n i}, a_{f i n}$ & depth of surface crack, initial and final depths of the surface crack \\
\hline bate $(a, c)$ & function of dimensions \\
\hline$c, c_{i n i}, c_{f i n}$ & half-length of surface crack, initial and final half-lengths of surface crack \\
\hline$\dot{a}$ & creep crack growth rate \\
\hline$n$ & Norton stress index in power law creep Eq. (3) \\
\hline$p$ & applied pressure \\
\hline$t_{i}$ & incubation time \\
\hline$\Delta a$ & incubation distance \\
\hline$\phi$ & constant in Eq. (1) \\
\hline$\phi_{i}$ & constant in Eq. (5) \\
\hline$\dot{\varepsilon}, \dot{\varepsilon}_{\min }$ & creep strain rate and minimum creep strain rates \\
\hline$\dot{\varepsilon}_{r e f}$ & creep strain rate at reference stress \\
\hline$\sigma$ & stress \\
\hline$\sigma_{b}, \sigma_{m}$ & bending stress, membrane stress \\
\hline$\sigma_{r e f}$ & reference stress \\
\hline$g(\zeta), \zeta$ & functions of geometry \\
\hline
\end{tabular}




\section{INTRODUCTION}

Failure of pressure vessels and piping systems that operate at high temperatures can occur by net section rupture, creep crack growth or a combination of both processes. Several design and assessment procedures are available for dealing with this situation. These include the French A16 [1], British Energy R5 [2] and BS 7910 [3] codes. Each of these procedures uses a combination of continuum mechanics and fracture mechanics concepts to make an assessment.

Although the procedures adopt the same basic principles by using the creep fracture mechanics term $C^{*}$ [4-5] for predicting the initiation of crack growth and crack growth rate, often different formulae are employed to make the calculations [1-3]. The main parameters that are used for deriving $C^{*}$ in components are reference stress, $\sigma_{r e f}$, and the stress intensity factor, $K$. It has been shown that predictions of creep crack growth can be very sensitive to the collapse mechanism assumed for determining the reference stress as well as to the material creep properties chosen [6]. In this paper, an analysis is performed to identify the appropriate formulae and material properties data to use to describe the cracking behaviour of pressurised straight and bent pipes containing semi-elliptical outer surface defects.

\section{Steady State Crack Growth Analysis}

Once a steady-state distribution of stress and creep damage has been developed ahead of a crack tip, it is usually found that creep crack growth rate $\dot{a}$ can be described by an expression of the form [7]:

$$
\dot{a}=D \cdot C^{* \phi}
$$

where $D$ and $\phi$ are material constants. Most often these constants are obtained from tests that are carried out on compact tension (CT) specimens according to the recommendations of ASTM E 1457-00 [8]. With this procedure, $C^{*}$ is estimated experimentally from measurements of creep load-line displacement. For components, such as pipes, $C^{*}$ must be determined from finite element analysis or reference stress methods. In this study, the reference stress procedure is adopted in line with that used in the defect assessment codes [1-3]. With this approach $C^{*}$ is expressed approximately as [9]: 


$$
C_{r e f}^{*}=\sigma_{r e f} \cdot \dot{\varepsilon}_{r e f} \cdot\left(\frac{K}{\sigma_{r e f}}\right)^{2}
$$

where $\dot{\varepsilon}_{r e f}$ is the creep strain rate at the appropriate $\sigma_{r e f}$ for the component and $K$ is the stress intensity factor corresponding to the applied loading. When the creep strain rate $\dot{\varepsilon}$ at an applied stress $\sigma$ can be described in terms of the Norton creep law [10]:

$$
\dot{\varepsilon}=A \cdot \sigma^{n}
$$

where $A$ and $n$ are material constants at constant temperature, Eq. (2) can be rewritten as:

$$
C_{r e f}^{*}=A \cdot \sigma_{r e f}^{n-1} \cdot K^{2}
$$

This equation will be used in the subsequent analysis to compare the cracking behaviour of the pipes with the materials properties data obtained from compact tension specimens.

\section{Crack Initiation Analysis}

When a structure containing a defect is first loaded the stress distribution is given by the elastic $K$-field or the elastic-plastic $J$-field. Therefore, time is required for the stresses to redistribute to the steady-state creep stress distribution controlled by $C^{*}$. During this period, transient conditions exist which are not uniquely defined by $C^{*}$. In addition, a time is needed for creep damage to develop around the crack tip [11]. Furthermore due to the practical limitations of crack detection equipment, the initiation of crack growth is difficult to determine precisely. Typically, this ranges between an extension $\Delta a$ of between about 0.1 and $0.5 \mathrm{~mm}$ depending on component and crack dimensions. ASTM E 1457-00 [8] identifies an extension of $0.2 \mathrm{~mm}$ for tests on CT specimens to cover the entire transition time to steady state conditions. This distance also takes into account the resolution of crack monitoring equipment. In this present work, it has been determined that $\Delta a=0.5 \mathrm{~mm}$ is a suitable value to choose for semi-elliptical defects in pipes.

From Eq. (1) it may be expected that the time, $t_{i}$, to initiate a crack extension of $\Delta a$ can be expressed by: 


$$
t_{i}=\frac{D_{i}}{C * \phi_{i}}
$$

where $D_{i}$ and $\phi_{i}$ are material constants. For steady state cracking $D_{i}$ is expected to be given approximately by $\Delta a / D$ with $\phi=\phi_{i}$. This equation assumes that the entire initiation period is governed by steady state value of $C^{*}$. This cannot be expected to be true during at least part of the initiation period $t_{i}$. The applicability of the equation will be examined for the pipes.

\section{Reference Stress Solutions}

It has been shown previously that although different codes employ Eq. (2), often different formulae are used to evaluate $K$ and $\sigma_{\text {ref }}$ [6]. Greater sensitivity of $C^{*}$ and cracking rate to reference stress than to $K$ is expected from Eq. (4) since $\phi$ in Eq. (1) is close to one, and typically $n \gg>1$. This has been demonstrated previously [6]. In the present work, solutions for $K$ due to Raju and Newman [12] have been used throughout: those for reference stress have been taken from R6 and are defined as $\sigma_{\text {ref } R 6 \text { Global }}$ [13-14] and $\sigma_{\text {ref }}$ R6 Local [15] to correspond with estimates that are based on 'global' and 'local' collapse, respectively. The same reference stress solutions have been used for the straight and bent pipes since it has been shown [16] that defects at the extrados or crown are not affected by the bend curvature and hence the bend may be treated as a straight cylinder.

\section{'Global' solution}

'Global' solutions of reference stress are based on collapse of the entire cross-section at the site of a defect. For a semi-elliptical axial outer surface defect in a pipe subjected to an internal pressure $p$, R6 gives [13-14]:

$$
\sigma_{\text {ref R6 Global }}=\frac{p}{\frac{1}{R_{e}-a} \cdot \operatorname{bate}(a, c)+\ln \left(\frac{R_{e}-a}{R_{i}}\right)}
$$

where bate $(a, c)$ is: 


$$
\operatorname{bate}(a, c)=\frac{a}{\sqrt{1+1.61 \cdot \frac{c^{2}}{\left[\left(R_{e}-a\right) \cdot a\right]}}}
$$

In these equations, $a$ is crack depth, $c$ is half crack length at the surface and $R_{i}$ and $R_{e}$ are the internal and external radii of the pipe, respectively.

\section{' Local' solution}

R6 uses a formula for 'local' collapse [15] of the ligament ahead of a crack based on Sattari-Far [17] to give:

$$
\sigma_{\text {refR Local }}=\frac{g(\zeta) \cdot \frac{\sigma_{b}}{3}+\sqrt{g^{2}(\zeta) \cdot \frac{\sigma_{b}^{2}}{9}+(1-\zeta)^{2} \cdot \sigma_{m}^{2}}}{(1-\zeta)^{2}}
$$

where

$$
\begin{aligned}
g(\zeta) & =1-20 \cdot \zeta^{3} \cdot\left(\frac{a}{2 c}\right)^{0.75} \\
\zeta & =\frac{a \cdot 2 c}{W \cdot(2 c+2 \cdot W)}
\end{aligned}
$$

In these equations, $W$ is pipe wall thickness and $\sigma_{b}$ and $\sigma_{m}$ are the linearised bending and membrane stresses across the crack plane as defined in BS 7910 [3].

\section{Experiments}

The 9\% Cr-steel examined was designated P91. Its chemical composition is shown in Table 1. All the pipe and compact tension specimens were taken from the same batch of steel. The study formed part of a European Union collaborative programme called 'HIDA' [7,18-19]. A total of 2 straight and 2 bent pipes was examined and all testing was carried out at $625^{\circ} \mathrm{C}$. Basic creep crack growth data were obtained on standard compact tension specimens with a thickness $B=25 \mathrm{~mm}$ containing $20 \%$ deep side-grooves on each side. The 
tests were performed at different laboratories using the same procedures. For the CT tests, the technique recommended in ASTM E 1457-00 [8] was adopted.

The dimensions of the straight pipes are shown in Fig. 1 and Table 2. Each had a nominal wall-thickness $W=20 \mathrm{~mm}$ and was provided with external axial semi-elliptical defects at locations D, in the heat-affected zone (HAZ) of the weld, and at E and F in the parent material (PM), as shown in Fig. 1. The initial and final depths, $a_{i n i}$ and $a_{f i n}$, and lengths $2 c_{i n i}$ and $2 c_{f i n}$, respectively, of each defect are given in Table 2 . These defects were introduced by electric discharge machining (EDM) which resulted in a crack tip radius of approximately $0.1 \mathrm{~mm}[18]$.

The test set up for the bent pipes is presented in Fig. 2 and the relevant dimensions are tabulated in Table 3. Both pipes were bent to $90^{\circ}$ and then subjected to a stress relief heattreatment which involved heating to $1065^{\circ} \mathrm{C}$, followed by fan assisted cooling to $300^{\circ} \mathrm{C}$ and tempering at $765^{\circ} \mathrm{C}$ for 3 hours in accordance with German specifications [20]. Each pipe had a nominal ID $=185 \mathrm{~mm}, \mathrm{OD}=225 \mathrm{~mm}$ (the same dimensions as the straight pipes, although there was some thinning as shown in Table 3 due to the bending operation) and was provided with 6 semi-elliptical axial defects on their outsides as indicated in Fig. 3. Three of the defects were situated along the extrados $\left(0^{\circ}\right)$ and 3 along the neutral axis as illustrated in Fig. 3. All defects were made using EDM, as described earlier, and their initial dimensions are given in Table 3 [19].

The test procedure for each pipe was very similar to each other [18-19]. The straight pipe tests were performed at JRC (Petten) and the bend pipe tests at SPG in Dresden. All were surrounded by a heating element which was buried in Vermiculite insulation to produce a uniform temperature. One of the bent pipes (SPG 1) was clamped in pin-jointed supports as illustrated in Fig. 2 to prevent axial expansion; the other was not restrained. All the pipes were raised to the test temperature of $625^{\circ} \mathrm{C}$ in steps of $100^{\circ} \mathrm{C}$ over a period of about 24 hours and allowed to stabilise at this temperature before being pressurised by Argon in about 30 seconds. During testing, the pressure was controlled using an electro-pneumatic controller. The test conditions were maintained within the limits of accuracy specified in the Code of Practice for the internal pressure testing of tubular components [21]. For the straight pipes crack growth was monitored by DC electrical potential methods and an AC system was employed for the bent pipes. It is considered that a resolution in crack extension 
between about 0.2 to $0.5 \mathrm{~mm}$ could be achieved with these techniques depending on the crack growth rate being monitored.

The loading conditions applied to each pipe are summarised in Table 4. Pipes ERA 1 and SPG 1 were subjected to a constant internal pressure although this pressure was increased after 1240 hours of testing for pipe SPG 1 since no change in potential was detectable. For pipes ERA 2 and SPG 2, the pressure was cycled between 0 and its maximum value at a frequency of $10^{-4} \mathrm{~Hz}$ (such that the maximum pressure was maintained for 9960 seconds for each cycle) except that no cycling was incurred between 1550 and 1990 hours for pipe ERA 2. The pipe tests were stopped either after a leak was detected or sufficient crack extension had taken place. For the straight pipes, the tests were interrupted after defect D, in the HAZ, had propagated through the wall. Both bent pipe tests were stopped prior to leakage.

\section{Experimental Results}

For the straight pipes, most crack growth occurred in the HAZ (defect D). The amount of crack extension that took place at defect $\mathrm{E}$ in the parent material is shown in Figs. 4 and 5. This only amounted to about $0.8 \mathrm{~mm}$ in both cases. On the other hand, there was no growth from defect $\mathrm{F}$ in either pipe. The results for defect $\mathrm{D}$ are not included since in this paper the intention is only to interpret cracking in the parent material. From Table 2, it can be seen that defects $\mathrm{D}$ and $\mathrm{E}$ had approximately the same initial size and defect $\mathrm{F}$ was the smallest. It is evident, therefore, from Figs. 4 and 5 that the HAZ material is more susceptible to cracking than the parent material and it is not surprising that no growth occurred from defect F. These figures clearly show the resolution in crack extension achievable with the crack monitoring system used. It is considered that an extension of $\Delta a=0.5 \mathrm{~mm}$ can be detected reliably [22]. The data were smoothed for subsequent analysis.

The experimental results for crack growth in the bent pipes are presented in Figs. 6 and 7. These figures indicate that the greatest amount of cracking occurred from the largest defect at the extrados (defect Y) followed by the same size of defect at the neutral axis (defect Q). This observation implies some influence from the bending operation, although it would seem that there is little effect of the method of end fixing at the supports. It is apparent that little crack growth occurred from the other defects except for defect $Z$ at the extrados of pipe SPG 2. No data were available for this defect in pipe SPG1. It should be noted that the crack extension for defects $\mathrm{Z}$ and $\mathrm{Q}$ are approximately the same, as shown in Fig. 7, even though 
the initial defect in $Z$ was nearly half of that of $Q$. This may suggest the importance of defect position for the present pipe bends.

For both straight and bent pipe tests, there is no obvious influence of cycling of pressure on the cracking rates measured (Figs. 4-7). This is mainly due to the low frequency dwell times of $10^{-4} \mathrm{~Hz}$ used. Furthermore, in all cases the fracture surfaces were seen to be predominantly intergranular $[19,22]$ suggesting pre-dominance of time-dependant cracking behaviour in the cyclic tests.

The data obtained from the compact tension tests are presented in Fig. 8. This figure shows creep crack growth rate $\dot{a}$ plotted against $C^{*}$ where $C^{*}$ has been determined experimentally from measured creep displacement rates in accordance with the procedure given in ASTM E 1457-00 [8]. It is evident that the results can be expressed in the form of Eq. (1) with the values of $D$ and $\phi$ given Table 5. The figure includes data that were obtained under static loading and cyclic loading at a frequency equal to or less than $10^{-2} \mathrm{~Hz}$. It is apparent that both the static and cyclic loading results can be accommodated within the same scatter band of plus or minus two standard deviations indicating little influence of fatigue on the cracking process at frequencies of $10^{-2} \mathrm{~Hz}$ or less. Also in both cases the fracture surfaces were mainly intergranular.

\section{Crack growth analysis}

In a previous study [6], it has been demonstrated that predictions of creep crack growth are sensitive to the uniaxial creep material properties and formulae used for calculating reference stress in Eqs. (2) and (4). Based on this study, values of $A$ and $n$, which are given in Table 6 , have been taken from measured minimum strain rates, $\dot{\varepsilon}_{m i n}$, to calculate $C^{*}$. Figure 9 compares predictions of the cracking behaviour of defect $\mathrm{Y}$ in bent pipe SPG 1, derived from different estimates of reference stress, with the CT scatter band. Also, Eqs. (6) and (8) have been employed in conjunction with both nominal wall thickness and local wall thickness (see Table 3) due to the thinning that occurred during the bending operation. It is evident from Fig. 9 that estimates of $C^{*}$ determined from reference stresses based on a 'local' collapse mechanism and the thinnest wall thicknesses result in the largest $C^{*}$ values and greatest deviation from the CT data band. In contrast, the use of nominal wall thickness combined with a 'global' estimate of reference stress gives the closest agreement. 
In Figure 10, comparisons of crack growth rates for most of the defects in the pipes using nominal wall thickness and 'global' estimates of reference stress in the $C^{*}$ expression (Eqs. (2) and (4)) are made with CT data. It is evident that broad agreement is achieved. This demonstrates that it is more appropriate to base $C^{*}$ on 'global' estimates of reference stress for semi-elliptical defects in pipes. Also, no distinction is observed between the straight and bent pipe data and also between the static and cyclic crack growth results.

Crack initiation data for the pipes assuming a crack extension of $\Delta a=0.5 \mathrm{~mm}$ are illustrated in Fig. 11. It is obvious that the time to reach this amount to cracking is less under cycling loading than under static loading conditions suggesting that cyclic loading accelerates the approach to steady state conditions. In addition, it is apparent that substitution of $D$ and $\phi$ from Table 5 into Eq. (5) for $D_{i}$ and $\phi_{i}$, for a crack extension of $\Delta a=$ $0.5 \mathrm{~mm}$, assuming steady state conditions, under predicts incubation times in Fig. 11. This is to be expected whilst damage is building up at a crack tip during the early stage of cracking [23].

\section{CONCLUSIONS}

Data on creep crack growth from external semi elliptical defects in pressurised straight and bent pipes of a $9 \% \mathrm{Cr}$-steel at $625^{\circ} \mathrm{C}$ have been reported. The results have been plotted in terms of the creep fracture mechanics parameter $C^{*}$. It has been shown that estimates of $C^{*}$ are sensitive to the formula used for calculating reference stress, the material properties chosen and the dimensions assumed for the pipe wall thickness. It has been found that good agreement is obtained with compact tension specimen data when comparisons are made with 'global' estimates of reference stress using nominal pipe wall thickness and with $C^{*}$ calculated from minimum creep strain rate uniaxial data.

Tests performed on straight and bent pipes have shown the same behaviour. Little difference in crack growth rate has been observed in pipe and compact tension results for experiments carried out under static and slow cyclic pressure loading. In all cases predominantly intergranular fracture surfaces were observed suggesting a creep dominated cracking mode. However, crack initiation was found to occur earlier when pressure was cycled than when it was held constant suggesting that cycling speeds the approach to steady 
state conditions. Furthermore predictions derived from Eq. (5), assuming steady state conditions, give shorter times to an initial crack extension of $\Delta a=0.5 \mathrm{~mm}$ compared to the experimental data.

\section{ACKNOLEDMENTS}

The authors would like to acknowledge the provision of data from the EU Brite/Euram 'HIDA' (1996-2000) project partners and the financial support from the European Community and British Energy Generation Ltd.

\section{REFERENCES}

1. Commissariat à l'Energie Atomique. A16: Guide for Defect Assessment and Leak Before Break Analysis, $4^{\text {th }}$ ed. Saclay: CEA, 2002.

2. Ainsworth, R. A. Editor R5: Assessment Procedure for the High Temperature Response of Structures, Nuclear Electric procedure R5 Issue2, 1999.

3. British Standard. BS 7910: Guide on Methods for Assessing the Acceptability of Flaws in Metallic Structures, BSI, 1999.

4. Landes, J. D. and Begley, J. A. A Fracture Mechanics Approach to Creep Crack Growth, ASTM STP 590, pp: 128-148, 1976.

5. Nikbin, K. M., Webster, G. A. and Turner, C. E. Relevance of Non-Linear Fracture Mechanics to Creep Cracking, Cracks and Fracture, ASTM STP 601, Pittsburgh, pp: 47-62, 1976.

6. Wasmer, K., Nikbin, K. M. and Webster, G. A. A Sensitivity Study of Creep Crack Growth in Pipes; PVP Vol 438, New and Emerging Computational Methods: Applications to Fracture, Damage and Reliability, pp: 17-24, ASME, New York, 2002

7. Tan, M., Celard, N. J. C., Nikbin, K. M. and Webster, G. A., Comparison of Creep Crack Initiation and Growth in Four Steels tested in HIDA, Int Jnl of Pressure Vessels and Piping 2001; 78(11-12): $737-747$.

8. ASTM. "ASTM E 1457-00: Standard Test Method for Measurement of Creep Crack Growth Rates in Metals", Annual Book of ASTM Standards, Vol 3, n 1, pp: 936950, 2001.

9. Ainsworth, R.A. Some Observations on Creep Crack Growth, Int Jnl of Fracture 1982; 20: 147-159.

10. Norton, F.H. The Creep of Steel at High Temperatures. Edited by McGraw and Hill. 
London, 1929.

11. Nikbin, K. M. Transition Effects in Creep-Brittle Materials, Mechanics of Creep Brittle Materials II', Eds A. C. F. Cocks, A.R.S. Ponter, Elsevier applied Science, pp: 14-24, 1991.

12. Raju, I. S. and Newman, J. C. Stress-Intensity Factors for Internal and External Surface Cracks in Cylindrical Vessels, Jnl of Pressure Vessel Technology 1982; 104: 293-298.

13. British Energy Generation Ltd. "R6: Assessment of the Integrity of Structures Containing Defects”. British Energy Generation Ltd 1996. UK, Report R6, version 1.4, Appendix M7-6, pp: M7-3-5.

14. Connors, D. C. A Compendium of Limit Loads, British Energy Generation Ltd 1996. Uk, Report M/TE/GEN/REP/0054/98.

15. British Energy Generation Ltd. R6: Assessment of the Integrity of Structures Containing Defects. British Energy Generation Ltd 2001. UK, Report R6, revision 4, Appendix IV.1.12.4, pp: IV.1.35.

16. Miller, A.G. Review of Limit Loads of Structures Containing Defects. Int Jnl of Pressure Vessels and Piping 1988; 32(2): 197-327.

17. Sattari-Far, I. Finite Element Analysis of Limit Loads for Surface Cracks in Plate, Int Jnl of Pressure Vessels and Piping 1994; 57(2): 237-243.

18. Le Mat Hamata, N. and Shibli, I. A. Creep Crack Growth of Seam-Welded P22 and P91 Pipes with Artificial Defects. Part I: Experimental Study and Post-Test Metallography, Int Jnl of Pressure Vessels and Piping 2001; 78 (11-12): 819-826.

19. Gampe, U. and Seliger, P. Creep Crack Growth Testing of P91 and P22 Pipes Bends, Int Jnl of Pressure Vessels and Piping 2001; 78 (11-12): 859-864.

20. VdTÜV-Werstoffblatt 511/2. Warmfester Stahl X10CrMoVNb 9-1, Ausgabe (09.1995).

21. "A Code of Practice for Internal Pressure Testing of Tubular Components at Elevated Temperatures", High Temperature Mechanical Testing Committee, October 1989.

22. Le Mat Hamata, N. and Shibli, I. A. Creep Crack Growth of Seam-Welded P22 and P91 Pipes with Artificial Defects. Part II: Data Analysis. Int Jnl of Pressure Vessels and Piping 2001; 78(11-12): 827-835.

23. Webster, G. A. and Ainsworth, R.A. High Temperature Components Life Assessment, Chapman \& Hall, London, 1994. 


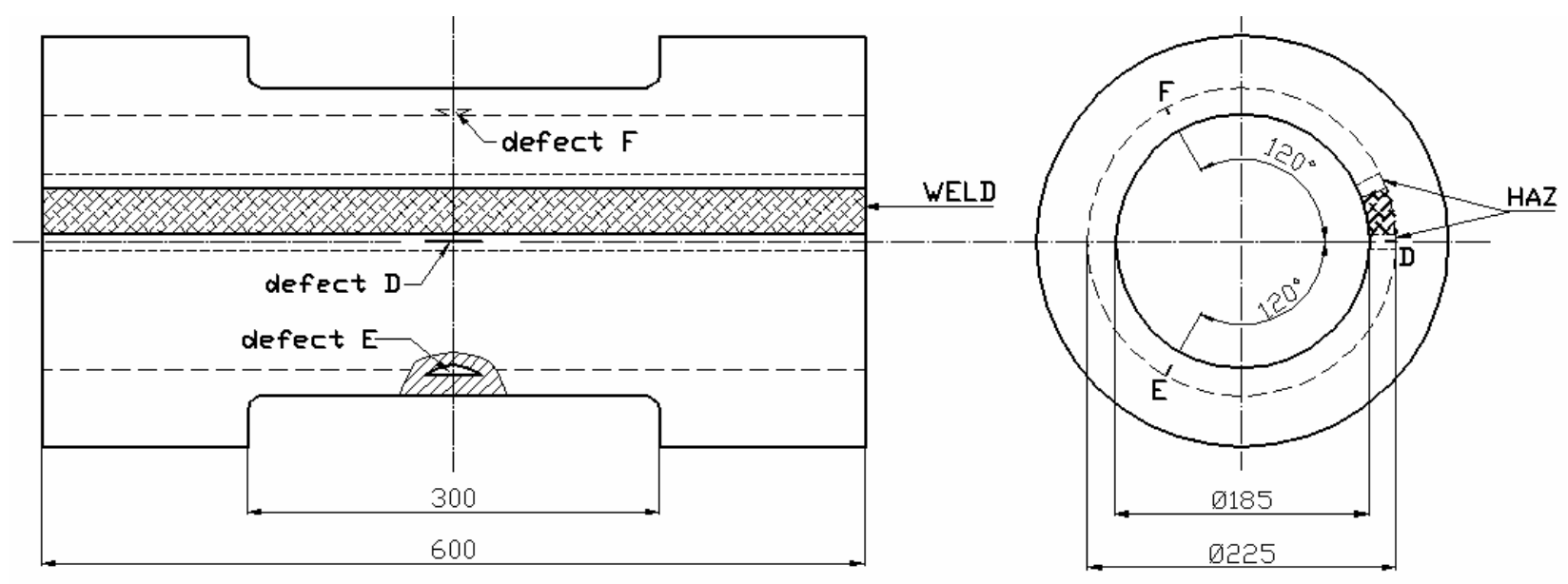

Figure 1: Geometry of the straight 'ERA' pipe showing location of external defects

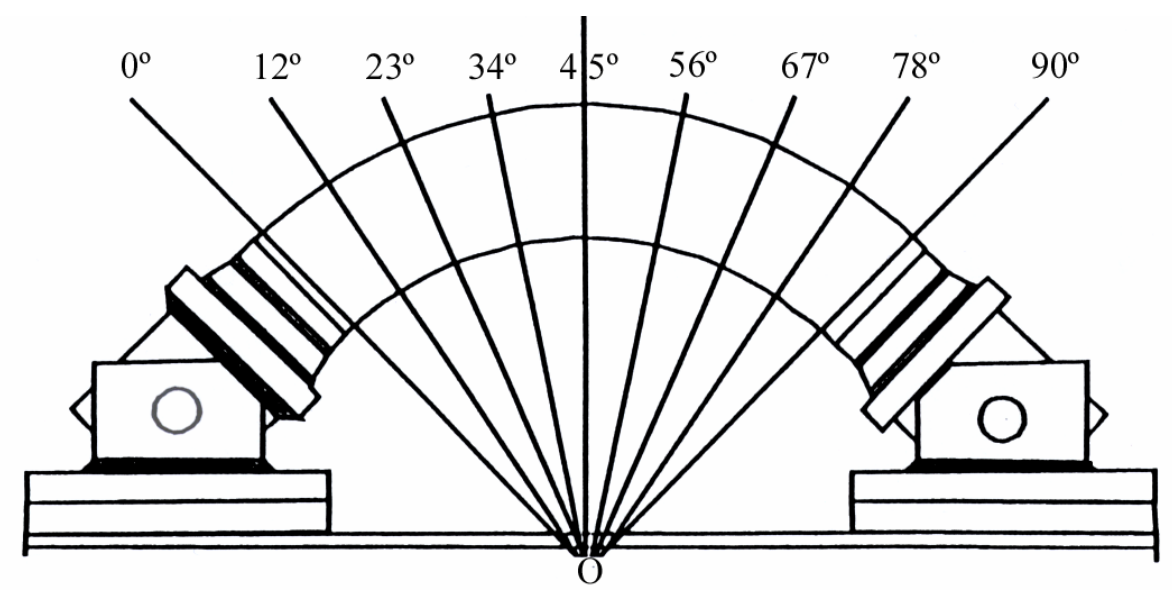

Figure 2: Bent pipe coordinate system with pined supported used for pipe SPG1

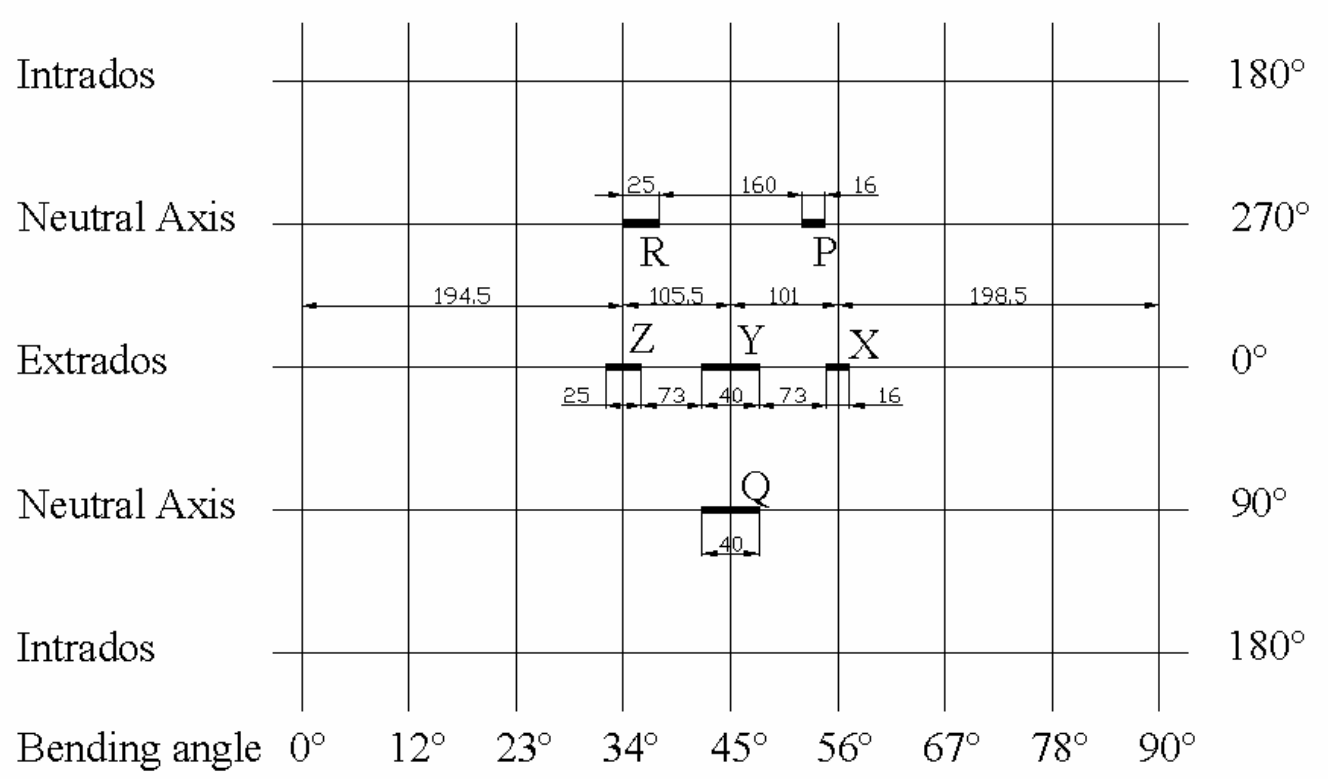

Figure 3: Geometry of defect positions in bent pipes SPG1 and SPG2. The details of the defects are given in Table 3 


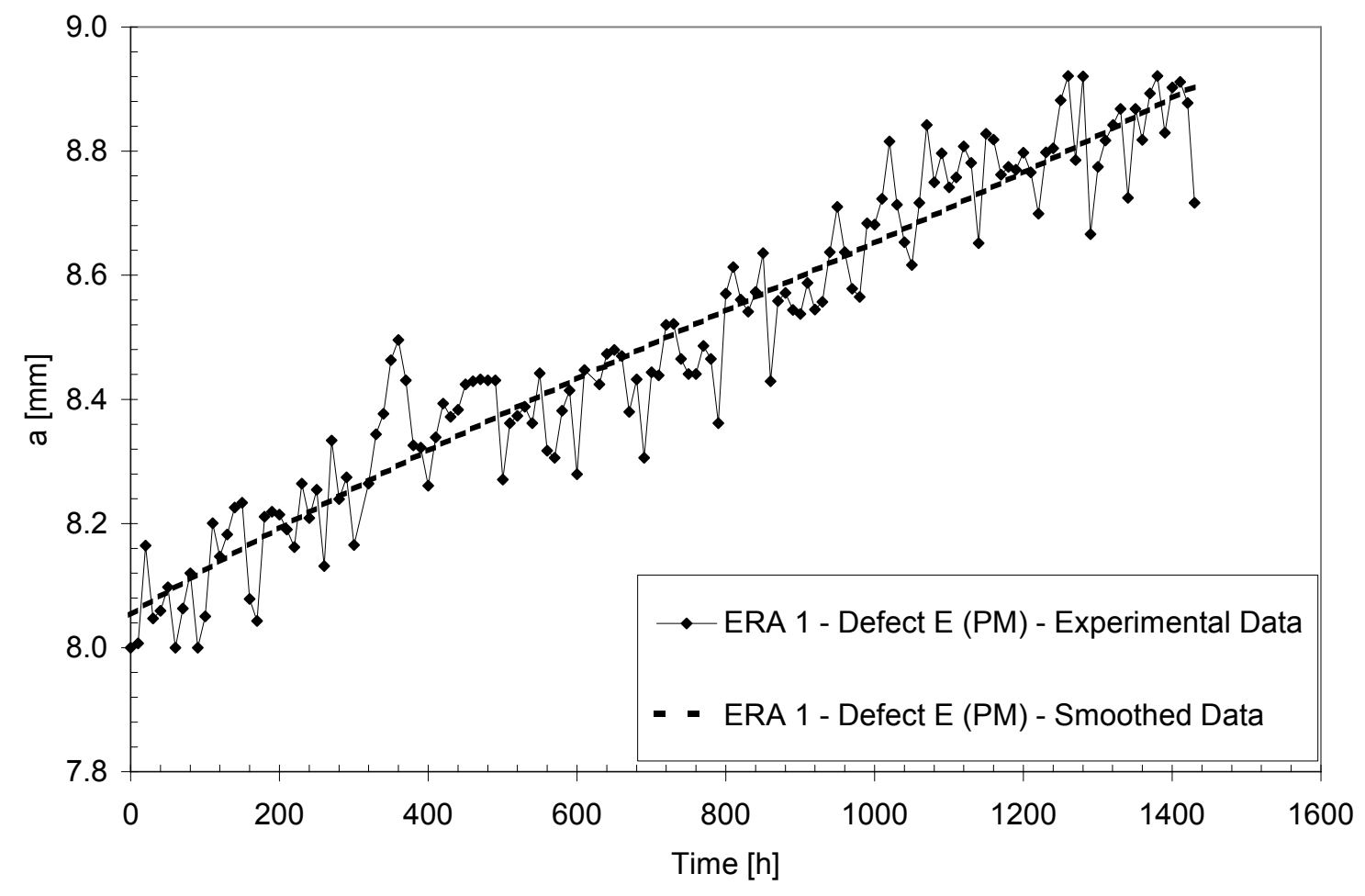

Figure 4: Creep crack growth for defect E in ERA1 pipe at $625^{\circ} \mathrm{C}$ showing the scatter in crack length measurements

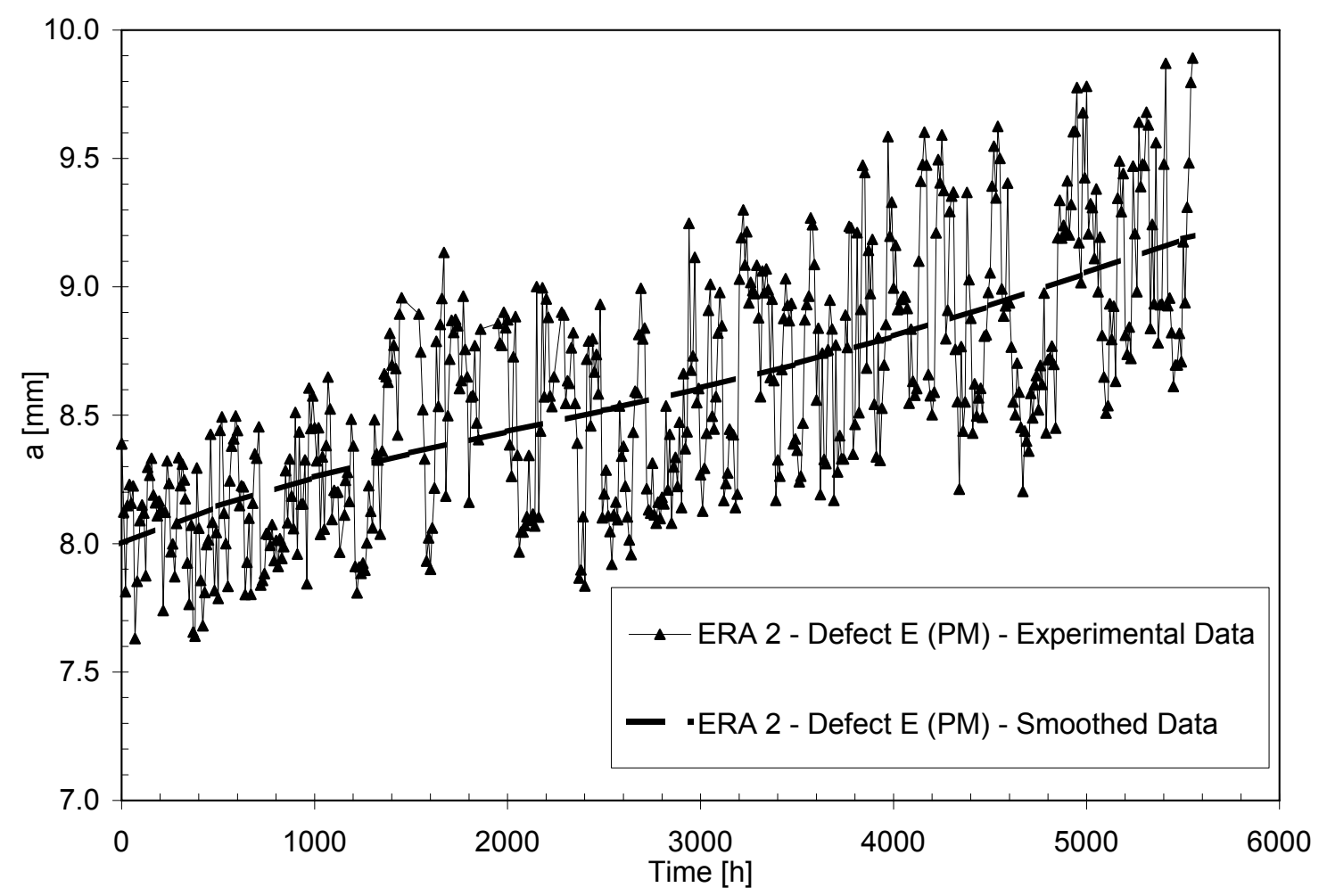

Figure 5: Creep crack growth for defect $\mathrm{E}$ in ERA2 pipe at $625^{\circ} \mathrm{C}$ showing a large scatter in the analysis of the results 


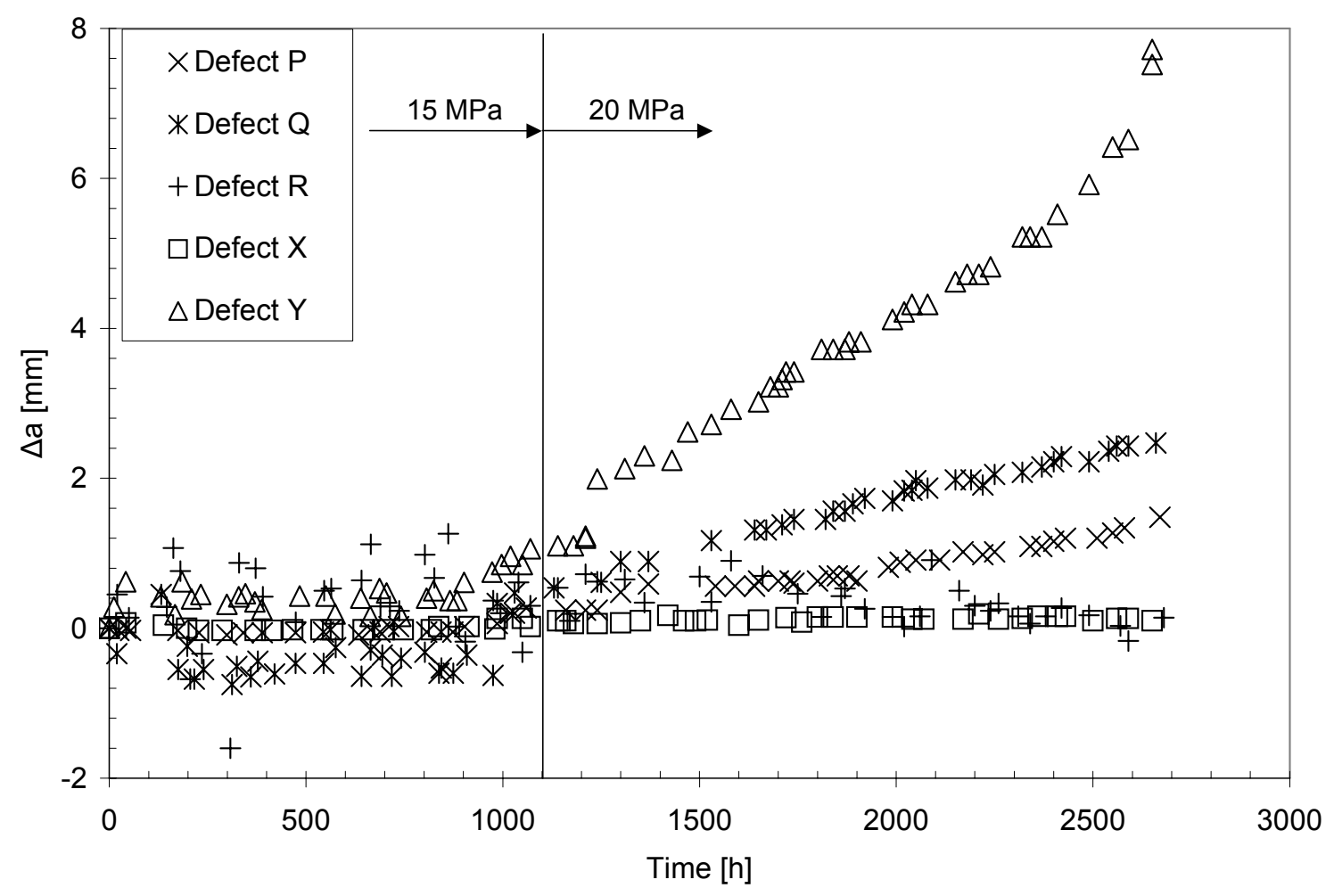

Figure 6: Creep crack growth for all defects in SPG1, P91 bent pipe at $625^{\circ} \mathrm{C}$ showing a pressure increase at the middle of the test

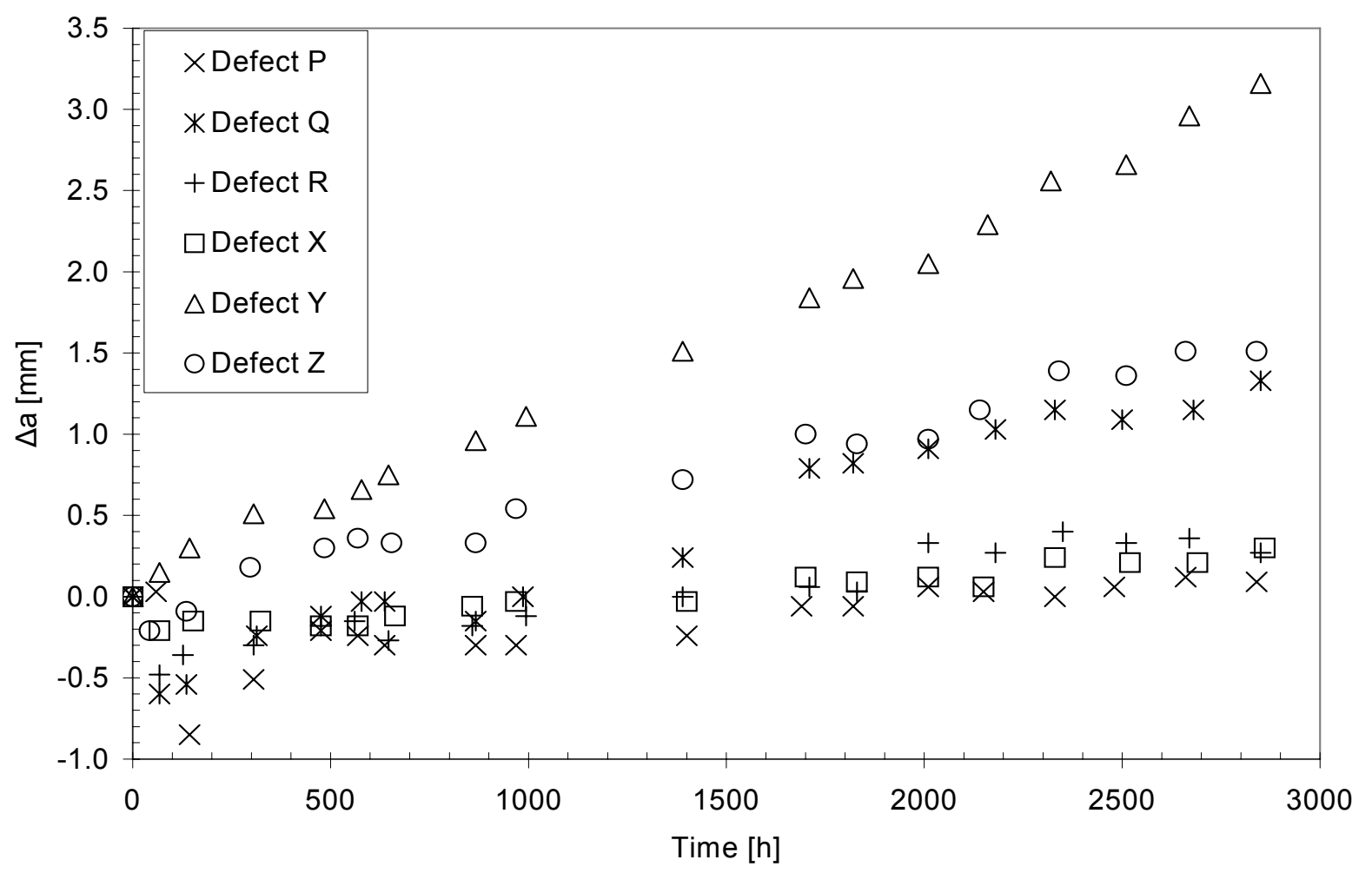

Figure 7: Creep crack growth extension for all defects in SPG2, P91 bent pipe at $625^{\circ} \mathrm{C}$ 


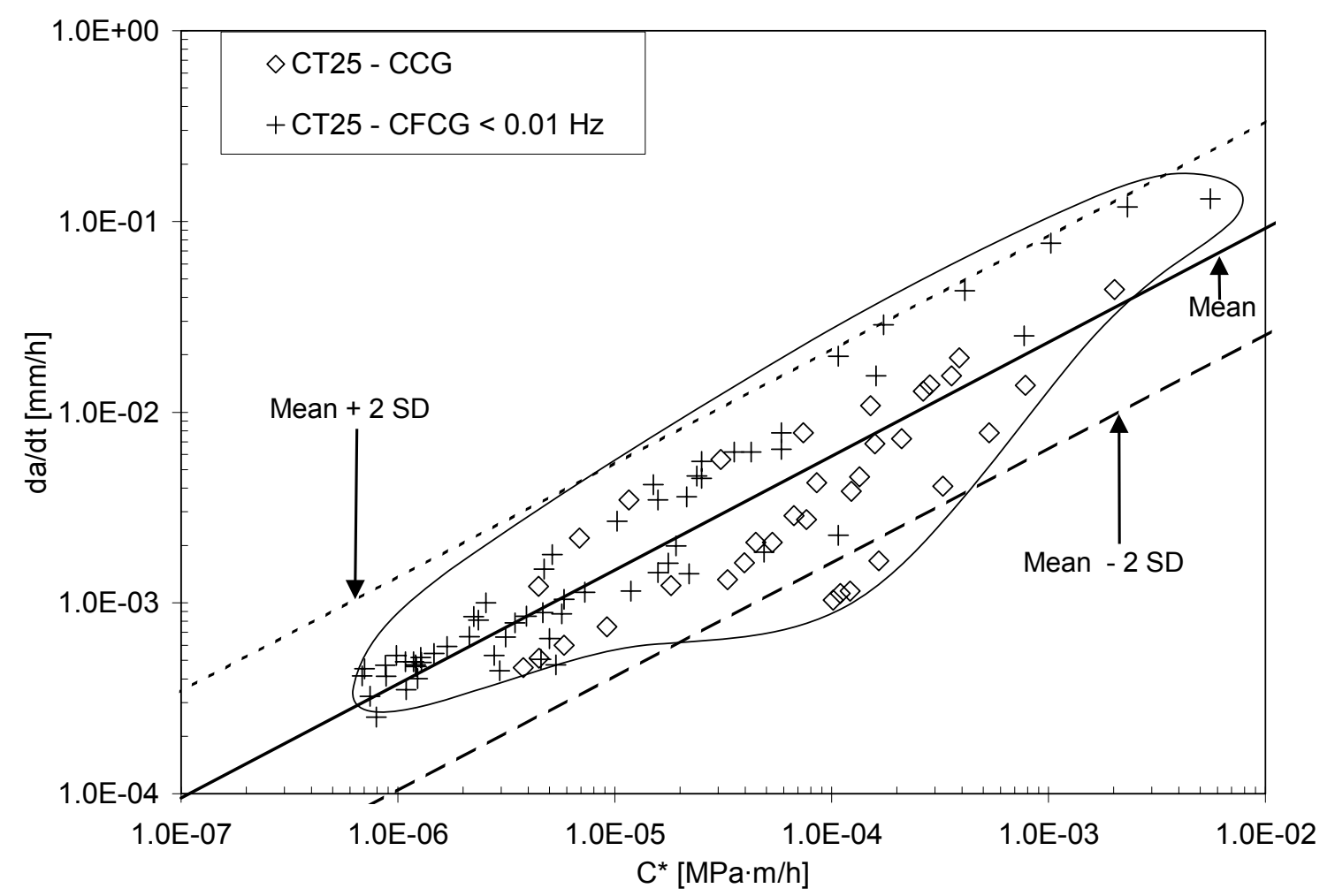

Figure 8: Comparison of static and slow cycle creep crack growth for P91 - PM - CT specimens at $625^{\circ} \mathrm{C}$

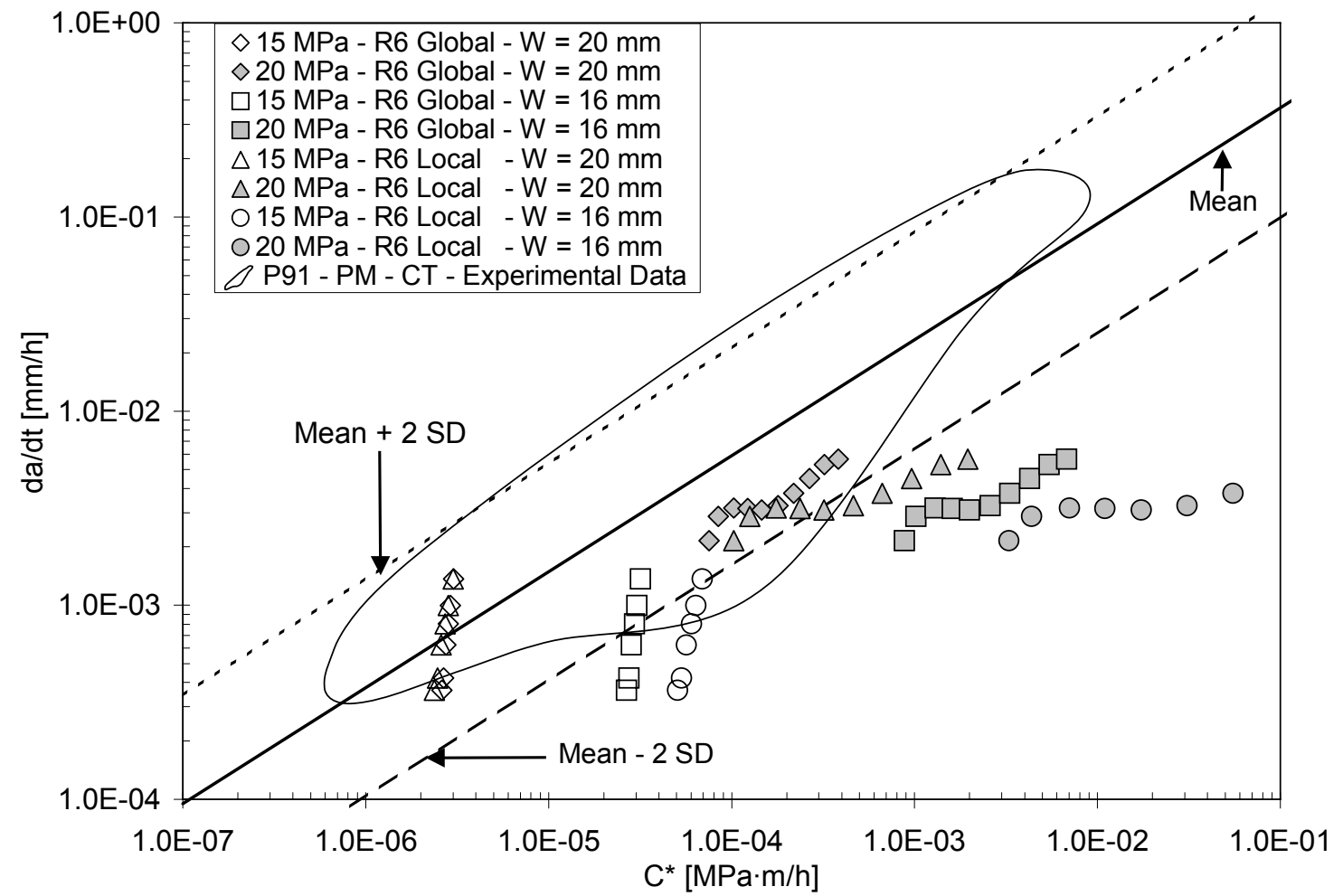

Figure 9: Comparison of cracking rates based on 'global' and 'local' $\sigma_{r e f}$ solutions for defect $\mathrm{Y}$ in bent pipe SPG1 using nominal and local thickness measurements at two different pressures 


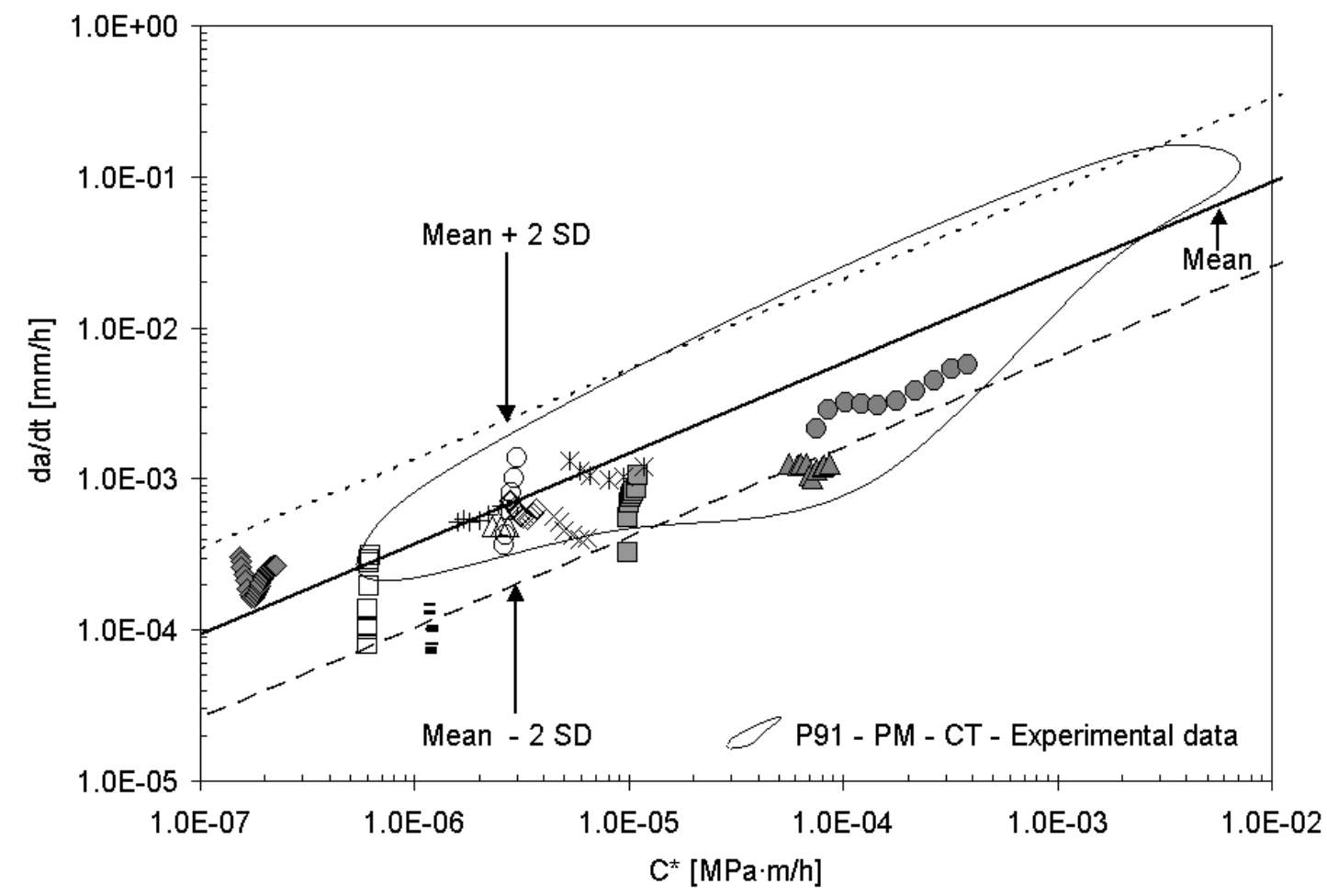

\begin{tabular}{|c|c|}
\hline$\diamond \mathrm{ERA} 1$ - Defect $\mathrm{E}-15 \mathrm{MPa}$ & $\diamond \mathrm{ERA} 2$ - Defect $\mathrm{E}-11 \mathrm{MPa}$ \\
\hline$\square$ SPG 1 - Defect P - $15 \mathrm{MPa}$ & $\square \mathrm{SPG} 1$ - Defect $\mathrm{P}-20 \mathrm{MPa}$ \\
\hline$\triangle \mathrm{SPG} 1$ - Defect $\mathrm{Q}-15 \mathrm{MPa}$ & $\triangle \mathrm{SPG} 1-$ Defect $\mathrm{Q}-20 \mathrm{MPa}$ \\
\hline SPG 1 - Defect $Y-15 \mathrm{MPa}$ & SPG 1 - Defect $Y-20 \mathrm{MPa}$ \\
\hline - SPG 2 - Defect P - $16 \mathrm{MPa}$ & $\times$ SPG $2-$ Defect $Q-16 \mathrm{MPa}$ \\
\hline$*$ SPG 2 - Defect $Y-16 \mathrm{MPa}$ & + SPG 2 - Defect $Z-16 \mathrm{MPa}$ \\
\hline
\end{tabular}

Figure 10: Comparison of creep crack growth rate for the pipe tests with the CT scatter band versus $C^{*}$, using global $\sigma_{r e f}$ and nominal thickness, for P91 pipes at $625^{\circ} \mathrm{C}$, showing no difference due to cyclic loading and loading history 


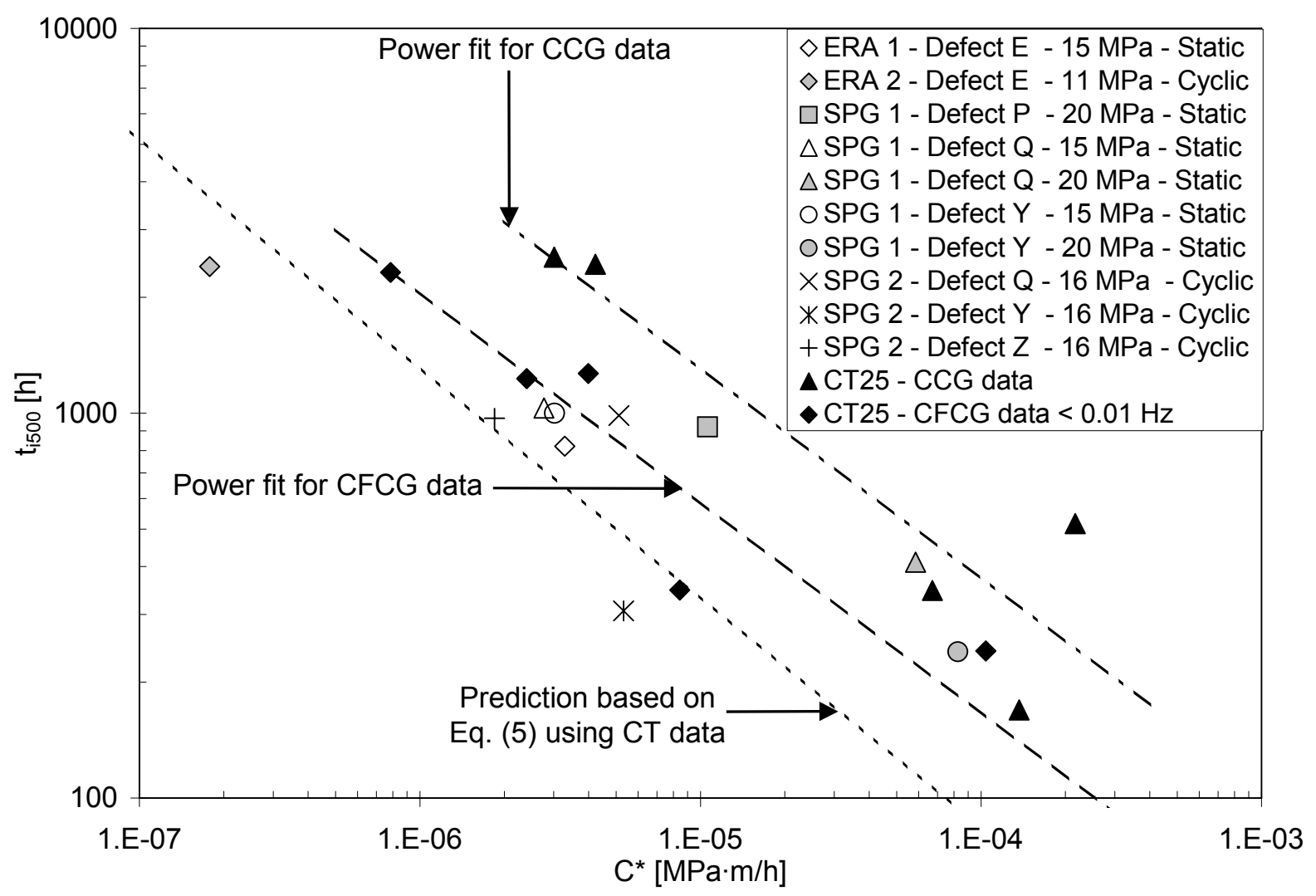

Figure 11: Effect of static and cyclic loading on time to crack initiation, $t_{i}$, based on a crack extension of $0.5 \mathrm{~mm}$ for $\mathrm{P} 91$ at $625^{\circ} \mathrm{C}$ for both $\mathrm{CT}$ and pipe specimens. 
Figure 1: Geometry of the straight 'ERA' pipe showing location of defects

Figure 2: Bent pipe coordinate system

Figure 3: Geometry of defect positions in bent pipes SPG1 and SPG2. The details of the defects are given in Table 3

Figure 4: Creep crack growth for defect E in ERA1 pipe at $625^{\circ} \mathrm{C}$ showing the scatter in crack length measurements

Figure 5: Creep crack growth for defect $\mathrm{E}$ in ERA2 pipe at $625^{\circ} \mathrm{C}$ showing a large scatter in the analysis of the results

Figure 6: Creep crack growth for all defects in SPG1 bent pipe at $625^{\circ} \mathrm{C}$ showing a pressure increase at the middle of the test

Figure 7: Creep crack growth extension for all defects in SPG2, P91 bent pipe at $625^{\circ} \mathrm{C}$

Figure 8: Comparison of static and slow cycle creep crack growth for P91 - PM - CT specimens at $625^{\circ} \mathrm{C}$

Figure 9: Comparison of cracking rates based on 'global' and 'local' $\sigma_{r e f}$ solutions for defect $\mathrm{Y}$ in bent pipe SPG1 using nominal and local thickness measurements at two different pressures

Figure 10: Comparison of creep crack growth rate for the pipe tests with the CT scatter band versus $C^{*}$, using global $\sigma_{r e f}$ and nominal thickness, for P91 pipes at $625^{\circ} \mathrm{C}$, showing no difference due to cyclic loading and loading history

Figure 11: Effect of static and cyclic loading on time to crack initiation, $t_{i}$, based on a crack extension of $0.5 \mathrm{~mm}$ for $\mathrm{P} 91$ at $625^{\circ} \mathrm{C}$ for both $\mathrm{CT}$ and pipe specimens 
Table 1: Chemical composition of P91 steel (Weight in \%)

\begin{tabular}{|c|c|c|c|c|c|c|c|c|c|c|c|}
\hline $\mathbf{C}$ & $\mathbf{M n}$ & $\mathbf{S i}$ & $\mathbf{S}$ & $\mathbf{P}$ & $\mathbf{C r}$ & $\mathbf{N i}$ & $\mathbf{M o}$ & $\mathbf{V}$ & $\mathbf{C u}$ & $\mathbf{N}$ & $\mathbf{A l}$ \\
\hline 0.091 & 0.409 & 0.369 & 0.013 & 0.028 & 8.440 & 0.270 & 0.920 & 0.240 & 0.040 & 0.038 & 0.070 \\
\hline
\end{tabular}


Table 2: Dimensions of defects in straight pipes ERA1 and ERA2

\begin{tabular}{|c|c|c|c|c|c|c|c|c|}
\hline Pipe & Defect & $a_{i n i}$ & $2 c_{i n i}$ & $a_{f i n}$ & $2 c_{i n i}$ & $2 c_{\text {fin }}$ & $a_{i n i} / c_{i n i}$ & $a_{\text {ini }} / W$ \\
\hline \multirow{3}{*}{ ERA1 } & D (HAZ) & 7.63 & 39.88 & 18.44 & 39.88 & 93.54 & 0.38 & 0.38 \\
\hline & $\mathrm{E}(\mathrm{PM})$ & 8.05 & 40.00 & 8.90 & 40.00 & Not Given & 0.40 & 0.40 \\
\hline & $\mathrm{F}(\mathrm{PM})$ & 5.00 & 25.00 & 5.00 & 25.00 & 25.00 & 0.40 & 0.25 \\
\hline \multirow{3}{*}{ ERA2 } & D (HAZ) & 8.00 & 43.68 & 15.72 & 43.68 & 96.76 & 0.37 & 0.40 \\
\hline & $\mathrm{E}(\mathrm{PM})$ & 8.00 & 40.00 & 8.87 & 40.00 & Not Given & 0.40 & 0.40 \\
\hline & $\mathrm{F}(\mathrm{PM})$ & 5.00 & 25.00 & 5.00 & 25.00 & 25.00 & 0.40 & 0.25 \\
\hline
\end{tabular}


Table 3: Dimensions of defects in bent pipes SPG1 and SPG2

\begin{tabular}{|c|c|c|c|c|c|c|}
\hline Notch & $\mathbf{P}$ & $\mathbf{Q}$ & $\mathbf{R}$ & $\mathbf{X}$ & $\mathbf{Y}$ & $\mathbf{Z}$ \\
\hline Position & $\begin{array}{c}\text { Neutral } \\
\text { axis }\end{array}$ & $\begin{array}{c}\text { Neutral } \\
\text { axis }\end{array}$ & $\begin{array}{c}\text { Neutral } \\
\text { axis }\end{array}$ & Extrados & Extrados & Extrados \\
\hline $\begin{array}{c}\text { Depth } \\
\left(a_{\text {ini } \text { in mm })}\right.\end{array}$ & 7.6 & 6.7 & 4.6 & 7.2 & 7.5 & 4.2 \\
\hline $\begin{array}{c}\text { Surface } \\
\left(2 c_{\text {ini }} \text { in mm }\right)\end{array}$ & 16 & 40 & 25 & 15.5 & 39 & 25 \\
\hline $\begin{array}{c}\text { Local thickness } \\
(W \text { in mm })\end{array}$ & 22 & 18 & 20 & 17 & 16 & 16 \\
\hline$a_{\text {ini }} / c_{\text {ini }}$ & 0.95 & 0.34 & 0.37 & 0.93 & 0.38 & 0.34 \\
\hline$a_{\text {ini }} / W$ & 0.35 & 0.37 & 0.23 & 0.42 & 0.47 & 0.26 \\
\hline
\end{tabular}


Table 4: Test information and loading conditions applied to each P91 pipe at $625^{\circ} \mathrm{C}$

\begin{tabular}{|c|c|c|c|c|c|}
\hline Test Id. & Test type & Mode of loading & No of Defects & $\begin{array}{l}\text { Pressure } \\
\text { [MPa] }\end{array}$ & Test duration [h] \\
\hline ERA1 & $\begin{array}{l}\text { Seam-Welded } \\
\text { straight pipe }\end{array}$ & Static & $\begin{array}{l}3 \text { external axial semi- } \\
\text { elliptical defects }\end{array}$ & 15 & 1430 \\
\hline ERA2 & $\begin{array}{l}\text { Seam-welded } \\
\text { straight pipe }\end{array}$ & Cyclic $\left(10^{-4} \mathrm{~Hz}\right)$ & $\begin{array}{l}3 \text { external axial semi- } \\
\text { elliptical defects }\end{array}$ & $0-11$ & 5550 \\
\hline SPG1 & Bent pipe & $\begin{array}{c}\text { Static } \\
\text { with end-constraint }\end{array}$ & $\begin{array}{l}6 \text { external axial semi- } \\
\text { elliptical defects }\end{array}$ & $\begin{array}{l}15 \\
20\end{array}$ & $\begin{array}{l}1240 \\
1520\end{array}$ \\
\hline SPG2 & Bent pipe & $\begin{array}{l}\text { Cyclic }\left(10^{-4} \mathrm{~Hz}\right) \\
\text { without constraint }\end{array}$ & $\begin{array}{l}6 \text { external axial semi- } \\
\text { elliptical defects }\end{array}$ & $0-16$ & 2850 \\
\hline
\end{tabular}


Table 5: Mean values of steady state creep crack growth parameters for P91 at $625^{\circ} \mathrm{C}$ obtained from CT specimen tests.

\begin{tabular}{|c|c|c|}
\hline Material Condition & $\boldsymbol{D}^{+}$ & $\boldsymbol{\phi}$ \\
\hline PM & 1.44 & 0.60 \\
\hline
\end{tabular}

${ }^{+}$Units correspond to cracking rate in $\mathrm{mm} / \mathrm{h}$ with $C^{*}$ in $\mathrm{MPa} / \mathrm{h}$. 
Table 6: Mean values of $A$ and $n$ (in Eq. (3)) obtained from uniaxial creep tests on P91 at $625^{\circ} \mathrm{C}$

\begin{tabular}{|c|c|c|c|}
\hline Mat. Cond. & Creep rate & $\boldsymbol{A}^{+}$ & $\boldsymbol{n}$ \\
\hline PM & $\dot{\varepsilon}_{\min }$ & $1.38 \mathrm{E}-22$ & 8.38 \\
\hline
\end{tabular}

${ }^{+}$Units correspond to strain rate in $1 / \mathrm{h}$ with stress in MPa. 